\title{
Bladder Dysfunction and Neuropathy in Diabetes
}

\author{
A. C. Buck, P. I. Reed, Y. K. Siddiq, G. D. Chisholm and T. Russell Fraser \\ Departments of Surgery and Medicine, Royal Postgraduate Medical School, Hammersmith Hospital, London, England
}

Summary. Established urodynamic and electrophysiological techniques have been applied to assess the frequency and extent of autonomic and peripheral neuropathy in 60 subjects with diabetes mellitus; 38 were diabetics with suggestive symptoms and the others were representative newly diagnosed (11) or treated (11) diabetics. Objective evidence of neuropathic bladder dysfunction was detected in 43 of them $(71.7 \%)$. The commonest abnormality was a hypotonic, insensitive large capacity bladder, which condition was usually asymptomatic. Less frequently $(15 \%)$ this was complicated by bladder decompensation and sphincter involvement, resulting in excessive residual urine and infection; some of these had bladder paralysis with chronic painless retention of urine $(7 \%)$. Electrophysiological studies found a sensory defect in the lower limbs in all tested patients $(100 \%)$, and in 41 patients $(69 \%)$ an associated motor conduction abnormality, which was more frequent and marked in the lower than the upper limb. These functional abnormalities appeared to be related to the severity of diabetes, but less to its duration. Indeed of 11 newly diagnosed diabetics tested $7 \mathrm{had}$ a peripheral neuropathy and 4 urodynamic abnormalities. The high incidence of bladder dysfunction and peripheral neuropathy in this series indicates the frequency of subclinical diabetic neuropathy and a factor needing more emphasis in diabetic uropathy.

Key words: Diabetic uropathy, peripheral neuropathy, bladder capacity, sensory and motor conduction.

For over 100 years vesical dysfunction and other neuropathies have been recognised as complications of diabetes mellitus. At first, bladder involvement was considered to be a late manifestation of poorly controlled diabetes $[1,2,3,4]$. However, recent studies with improved techniques have shown not only a high incidence of both autonomic and peripheral neuropathy, even at the time of the initial diagnosis $[5,6,7$, $8,9,10]$, but also that the condition may at times be asymptomatic $[11,12,13]$. Therefore, in an effort to define the incidence and clinical features of diabetic neuropathy, we have carried out a combined urodynamic/electrophysiological study on some of our diabetic patients, choosing some with evident neuropathic features, some presenting with diabetic retinopathy problems, some with urinary frequency without obvious cause as well as some on routine treatment and some newly diagnosed.

\section{Material and Methods}

Sixty diabetic patients, 35 males and 25 females, were studied, after the purpose of investigation had been explained to them and their co-operation obtained. The patients were a highly selected group chosen to assess both the frequency of evidence of vesical dysfunction and of neuropathy in certain diabetic groups whose features are summarised in Table $1 \mathrm{a}$. Twentyseven patients were chosen because of neuropathic features and/or urinary symptoms not obviously due to infection, 11 as subjects presenting with diabetic retinopathy and the others were either apparently uncomplicated treated diabetics [11] or newly diagnosed subjects presenting with a typical diabetic syndrome.

Twenty-nine patients were diabetics with urinary symptoms; often [15] frequency and/or dysuria, or in 10 , symptoms of prostatic outflow tract obstruction. Three had been admitted with acute retention of urine, and 4 had presented with chronic painless re- 
Table 1a. Some features of the patients studied; including the frequency of neuropathic symptoms and signs, in the various selection groups

\begin{tabular}{|c|c|c|c|c|c|c|}
\hline \multirow{2}{*}{$\begin{array}{l}\text { Grouping } \\
\text { (by reason for inclusion) }\end{array}$} & \multirow{2}{*}{$\begin{array}{l}\text { No. } \\
\text { (M/F) }\end{array}$} & \multirow{2}{*}{$\begin{array}{l}\text { Age } \\
\text { Range }\end{array}$} & \multicolumn{4}{|c|}{ Diabetic management } \\
\hline & & & Nil & Diet & Tablets & Insulin \\
\hline \multicolumn{7}{|l|}{$\begin{array}{l}\text { Diabetics with } \\
\text { associated features: }\end{array}$} \\
\hline 1. Urinary symptoms & $5 / 2=7$ & $33-68$ & - & 3 & 1 & 3 \\
\hline 2. Neuropathic symptoms & $3 / 2=5$ & $34-59$ & - & 1 & 0 & 4 \\
\hline 3. Both previous & $6 / 9=15$ & $29-75$ & - & - & 7 & 8 \\
\hline 4. Retinopathy & $9 / 2=11$ & $23-48$ & - & - & 1 & 10 \\
\hline \multicolumn{7}{|l|}{ Others } \\
\hline Treated diabetics & $6 / 5=11$ & $20-80$ & - & 3 & 2 & 6 \\
\hline Newly diagnosed diabetics & $6 / 5=11$ & $20-70$ & 11 & - & - & - \\
\hline Total & $35 / 25=6$ & $20-80$ & 11 & 7 & 11 & 31 \\
\hline
\end{tabular}

Table $1 \mathrm{~b}$. Some features of the patients studies; including the frequency of neuropathic symptoms and signs, in the various selection groups

\begin{tabular}{|c|c|c|c|c|c|}
\hline $\begin{array}{l}\text { Percent with } \\
\text { Symptoms } \\
\text { Urinary }\end{array}$ & \multicolumn{2}{|l|}{ Neuropathy } & $\begin{array}{l}\text { Neuropathy } \\
\text { signs }\end{array}$ & Impotence & Retinopathy \\
\hline$(100 \%)$ & $29 \%$ & - & $71 \%$ & $40 \%$ & $43 \%$ \\
\hline- & $20 \%$ & $(100 \%)$ & $(100 \%)$ & $100 \%$ & $40 \%$ \\
\hline$(100 \%)$ & $27 \%$ & $(100 \%)$ & $(100 \%)$ & $83 \%$ & $33 \%$ \\
\hline $18 \%$ & $45 \%$ & $55 \%$ & $82 \%$ & $44 \%$ & $(100 \%)$ \\
\hline $9 \%$ & $18 \%$ & $36 \%$ & $36 \%$ & $50 \%$ & $9 \%$ \\
\hline $36 \%$ & $18 \%$ & $45 \%$ & $28 \%$ & $67 \%$ & $18 \%$ \\
\hline $48 \%$ & $27 \%$ & $\begin{array}{l}57 \% \\
80 \%\end{array}$ & $68 \%$ & $60 \%$ & $40 \%$ \\
\hline
\end{tabular}

tention of urine with overflow incontinence. In 18 of these 29 patients with urinary symptoms there was bacteriological evidence of recent or current urinary infection.

Thirty-four patients (56\%) had peripheral neurological symptoms, which included paraesthesiae mainly in the lower extremities. Objective clinical signs of neuropathy, such as absent tendon reflexes, impaired vibration and position sense were noted in 41 patients $(68 \%) ; 23$ males and 18 femals. Only 12 patients $(20 \%)$ had neither symptoms nor signs of a peripheral neuropathy. Twenty-one of the 35 male patients $(60 \%)$ complained of impotence or ejaculatory disturbances (Table $1 \mathrm{~b}$ ) (In 4 patients treated with pituitary ablation the impotence antedated the operation). Fifteen patients were diabetics of juvenile type, i. e. with the onset of diabetes occurring under the age of 40 years, who had been on treatment with insulin for many years.

1. Urodynamic measurements were performed by means of established techniques which have been described previously [14]; the measurements made included (a) urine flow rates, (b) catheter residual urine volumes, (c) the urethral pressure profile, (d) cystometry, (e) bladder sensation. Figures 1 and 3 give illustrative tracings of (a), (c) and (d).

Urine flow rates were measured by means of a direct reading uroflowmeter. Peak urine flow rates were recorded, the normal range being $15-40 \mathrm{ml} / \mathrm{sec}$ [15]. Residual urine volumes of less than $50 \mathrm{ml}$ were regarded as normal. The urethral pressure profile was performed according to the method described by Brown and Wickham [16]. On cystometry intrinsic vesical pressures above $15 \mathrm{cms} \mathrm{H}_{2} \mathrm{O}$, when the bladder 
capacity did not exceed $500 \mathrm{ml}$, were regarded as normal. Bladder sensation was evaluated by expressing the volume at which awareness of filling was just noted as a percentage of the total bladder capacity; normally this is less than $50 \%$.

2. Electrophysiological measurements, following a detailed clinical neurological examination, were performed on the same day or within a few days of the urodynamic studies. The peripheral nerve conduction studies were nearly always performed in the right leg and forearm, but sometimes, for technical reasons, on the opposite limbs. The room temperature was kept constant between $22^{\circ}$ to $25^{\circ} \mathrm{C}$ and standard techniques were employed. A "MEDELEC MS5" machine with a direct ultra violet recorder and AVM 5 Evoked Response Averager were used, each measurement being performed twice and the result averaged. The following measurements were obtained:

a. lateral popliteal nerve motor latencies and conduction velocity

b. sensory nerve latency and action potential amplitude

c. median nerve motor latency and conduction velocity

d. sensory nerve latency and action potential amplitude.

Motor latencies and conduction velocity in the lateral popliteal nerve were measured after placing a co-axial needle electrode (the cathode) in the extensor digitorum brevis muscle, the anode being a metal plate $3.5 \mathrm{cms} \times 6 \mathrm{cms}$ strapped to the dorsum of the foot with electrode jelly to ensure good contact. The stimulating electrodes were placed over the anterior aspect of the ankle and behind the neck of the fibula. The latencies were measured from a permanent photographic record corresponding to the oscillographic readings [17]. A square wave impulse of 0.1 millisecond duration and of variable intensity up to 250 volts, repeated once every second, was employed, the stimulus being progressively increased until supramaximal stimulation was obtained at both sites in turn. The distance between the two sites was measured and the conduction velocity calculated and expressed in metres per second. Lateral popliteal nerve sensory latency and action potential measurements were made according to the method described by Gilliatt, Goodman and Willison [18]. The stimulus was of variable intensity up to 100 volts and of constant duration ( 0.1 millisecond) and repeated once every second, one hundred sweeps being stored, averaged and recorded on the oscilloscope. The record was then photographed and the latency and action potential amplitude measured from it.

Motor latencies and conduction velocity in the median nerve were measured similarly. The recording

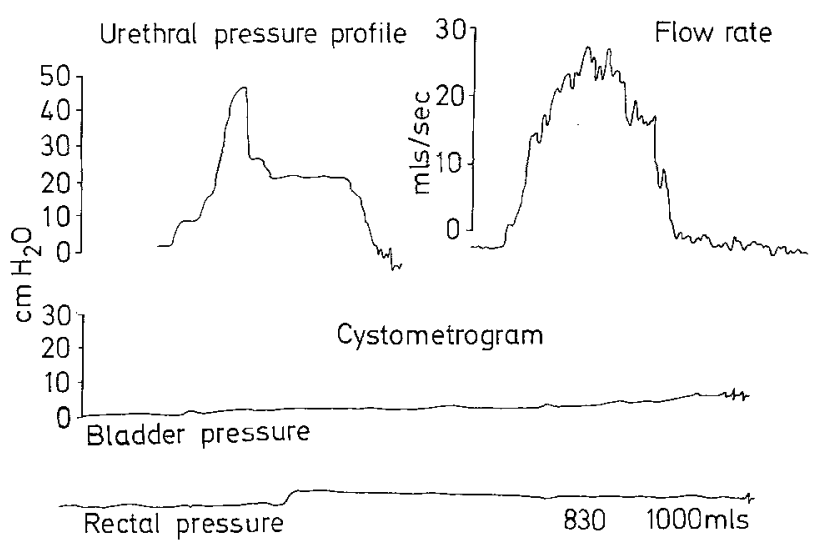

Fig. 1. Urodynamic recordings from Case 1. J. G. (Male, 31 years, diabetes 21 years, asymptomatic), implying the typical hypotonic insensitive large bladder of diabetic neuropathy.

Urethral pressure profile $=$ normal.

Peak urine flow rate $=30 \mathrm{ml} / \mathrm{s}$ (normal).

Cystometrogram $=$ flat with (bladder capacity $=1000 \mathrm{ml}$, first filling sensation at $830 \mathrm{ml}$ )

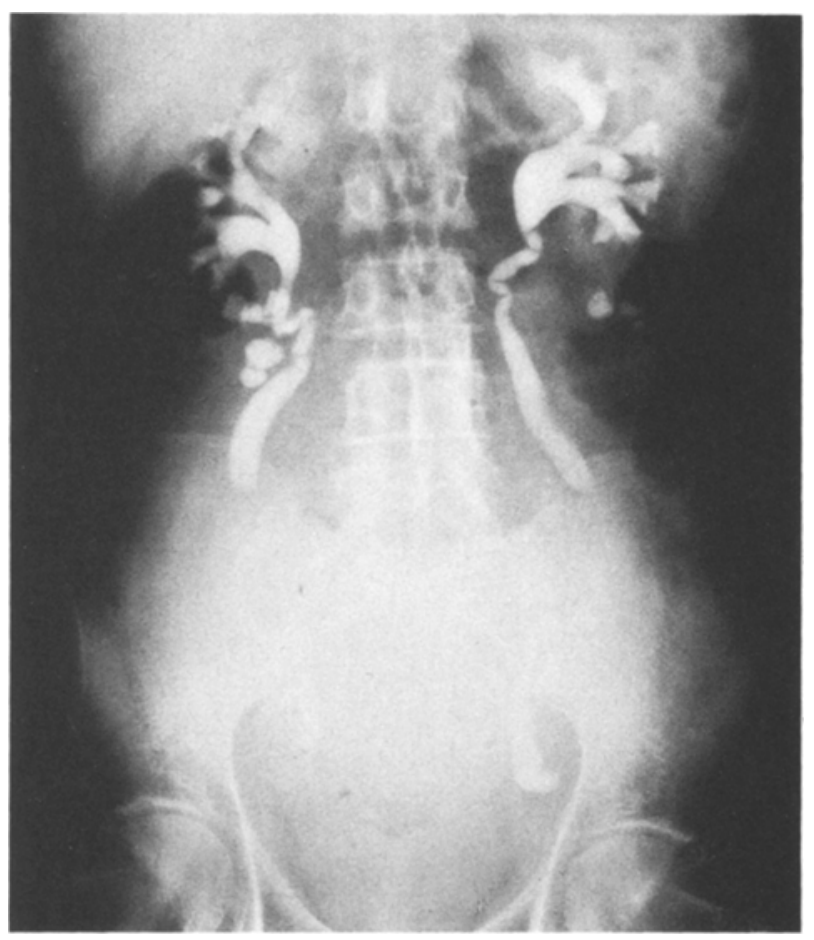

Fig. 2. Post micturition film of I. V. P. in Case 1. J. G. Note gross distension of bladder and upper urinary tract 


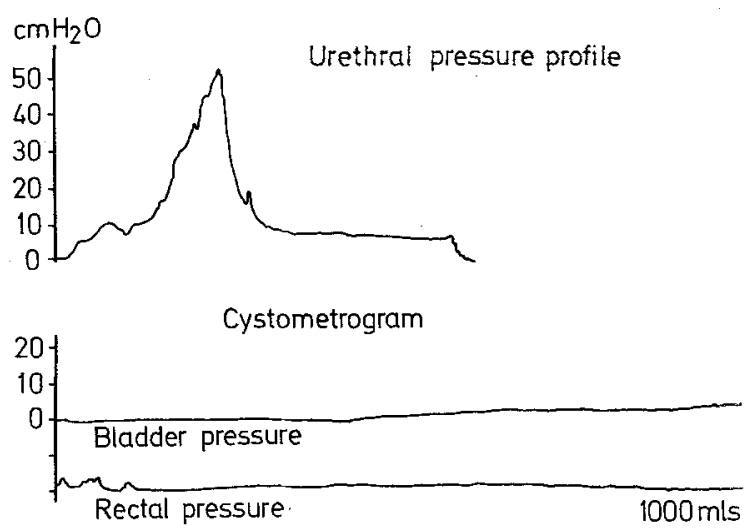

Fig. 3. Urodynamic recordings from Case 2. H. C. (Male, 69 years, diabetes 39 years).

Urethral pressure profile $=$ nomeln

No urine flow (retention).

Flat cystometric tracing with absent sensation.

Residual urine $=3000 \mathrm{ml}$ (without clinical evidence of outflow tract obstruction)

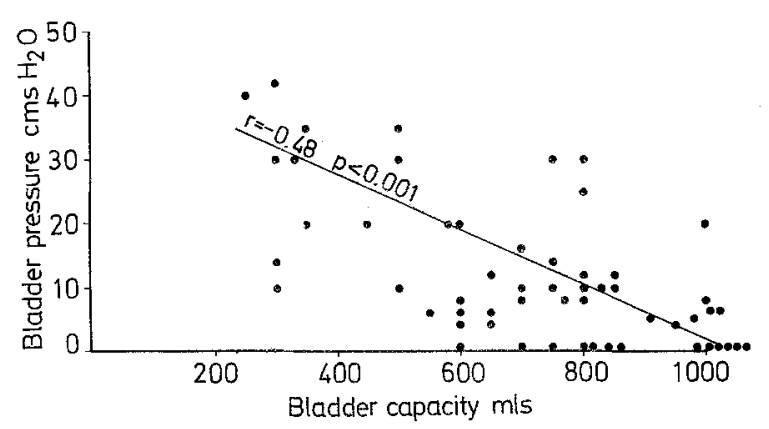

Fig. 4. Correlation between bladder capacity and pressure (among 55 subjects without evidence of outflow tract obstruction)

co-axial needle electrode was placed in the abductor pollicis brevis muscle and the stimulating surface electrodes over the median nerve at the distal skin crease at the wrist and the antecubital fossa.

Sensory latency and action potential amplitude measurements in the median nerve were obtained employing the method of Dawson [19]. The recording electrodes, two metal strips $20 \mathrm{~mm} \times 5 \mathrm{~mm}$ and mounted $4 \mathrm{cms}$ apart, were placed over the median nerve at the wrist, the distal electrodes lying over the distal skin crease. The stimulating electrodes were two silver, felt lined strips placed around the index finger; the anode at the distal interphalangeal joint and the cathode as close to the base of the finger as possible. Using the same stimulus, the measurements were made in the same way as on the leg.

The same examination was carried out in 48 nondiabetic subjects without evidence of neuropathy and matched for age and sex. Student's ' $t$ ' test was used for comparison of the means between the diabetic patients and the non-diabetic controls.

\section{Reswits}

\section{Urodynamic Measurements}

In $48 / 60(80 \%)$ of all patients we found urodynamic abnormalities implying either autonomic neuropathy or mechanical outflow tract obstruction; the remaining 12 gave normal records. In Figure 5 are shown the peak urine flow rates, the residual urine volumes and the bladder capacities found for all 60 patients.

The peak flow rate was normal in the majority, excepting only two groups of results; those in 5 patients who were found to have outflow tract obstruction in whom this was implied from an abnormal urethral pressure profile, and those in 9 patients where the loss of detrusor activity and/or neuropathic sphincter involvement, as well as their abnormal cystometry, were due to diabetic neuropathy. The former 5 patients, all male, were aged $48-75$ years, had had symptoms and signs suggestive of bladder outflow tract obstruction, and were found to have not only low urine flow rates, but also abnormal urethral pressure profiles along with normal cystometrograms, supporting the clinical diagnosis of obstruction. One patient had a strictured urethra and in the other 4 , the prostate was found enlarged on rectal examination. Three of these patients had been admitted with acute retention of urine when diabetes had been an incidental finding.

In 43 patients $(71.6 \%$ of all 60$)$, however, evidence was found of bladder abnormalities implying autonomic neuropathy; all 43 had excessively large bladder capacities $(>500 \mathrm{ml})$. The mean bladder capacity in these was $937 \mathrm{ml}$ and a negative correlation ( $r=-0.48 \mathrm{P}<0.001)$ was seen between bladder capacities and pressures denoting hypotonicity (Fig. 4). Among these 43 subjects with abnormally large bladder capacities, bladder sensitivity was also reduced, the first sensation of bladder filling was noted only when the bladder filling had reached $78.7 \pm 3.4 \%$ (mean SEM) of capacity. This contrasts with those with normal bladder capacity $(<500 \mathrm{ml})$ becoming aware of filling sensations at $47.7 \pm 6.6 \%$ of capacity ( $P$ for the difference $<0,001$ ).

A grading of the cystometric abnormalities found due to autonomic neuropathy and their frequency is shown in Table 2 . Twelve patients $(20 \%)$ had no demonstrable uropathy (Grade 0 ). Thirty-four patients $(57 \%)$ had a hypotonic, insensitive, large capacity bladder, usually with no associated urinary symptoms (Grade I Uropathy). Five patients ( $8 \%$ ) had, in addition, loss of detrusor activity and sphincter dysfunction resulting in excess residual urine (Grade II). The other 4 patients $(7 \%)$ had complete bladder paralysis with retention of urine and overflow incontinence (Grade III Uropathy). 
Among the 34 patients with large hypotonic and insensitive bladders (Grade I Uropathy), the mean bladder capacity was $807 \pm \mathrm{SD} 298 \mathrm{ml}$, the mean intrinsic bladder pressure $9 \mathrm{cms}\left(\mathrm{H}_{2} \mathrm{O}\right)$, and bladder sensation was diminished or absent. The cystogram showed a flat tracing with little or no pressure rise on filling to capacity. However, peak urine flow rates and catheter residual urine volumes were normal $(<50$ $\mathrm{ml}$ ) and 23 of 34 patients had no urinary symptoms, being able to empty their bladders satisfactorily on voiding, but unaware of the large volume contained in the bladder, as illustrated by the following example:

Case 1. JG was a 31 year old man with severe diabetes for 21 years. Diabetes was well controlled with insulin, a pituitary implant had been carried out for retinopathy. The patient had no urinary complaints. The MSU was sterile on culture. Urodynamic measurements showed that the urethral pressure profile tracing was normal, the peak urine flow rate was $30 \mathrm{ml} / \mathrm{sec}$. The cystometrogram showed a flat tracing with a capacity of $1000 \mathrm{mls}$ and there was no sensation of bladder filling before $830 \mathrm{ml}$ (Fig. 1).

In 5 other patients this large capacity, hypotonic and insensitive bladder was found associated with the further abnormalities of excessive residual urine volume (100-340 ml) and poor urine flow rates (less than $15 \mathrm{ml} / \mathrm{sec}$ ) on voiding (Grade II Uropathy).

The 4 remaining patients had presented with complete bladder paralysis i. e. voiding flow rates were unobtainable and catheterization demonstrated residual urine volumes of $600,1200,2130$ and $3000 \mathrm{ml}$ (Grade III Uropathy). Bacteriological evidence of urinary infection was present in all these patients with poor urinary flow rates and excessive residual urine. The following is an example of the paralysed bladder:

Case 2. $\mathrm{HC}$ was a male aged 69 years with insulin dependent diabetes for 39 years. The patient was referred from the diabetic clinic with recent complaint of painless urinary incontinence and dribbling, believed to be due to prostatic enlargement. The bladder was distended to the level of the umbilicus, but on rectal examination the prostate was not enlarged. An MSU grew E. Coli. I. V. P. showed obstructive uropathy with dilated upper urinary tracts and gross distention of the bladder (Fig. 2). Urodynamic measurement showed a residual urine volume of $3000 \mathrm{ml}$, but no flow rate was obtained. The urethral pressure profile was low in the region of the bladder neck where the peak urethral pressure, representing the external sphincter pressure was $50 \mathrm{~cm} \mathrm{H}_{2} \mathrm{O}$. The cystometrogram showed a flat curve with no sensation of bladder filling (Fig. 3). At cystoscopy the bladder mucosa was pale and featureless, the posterior urethra was wide and there was no evidence of prostatic enlargement.

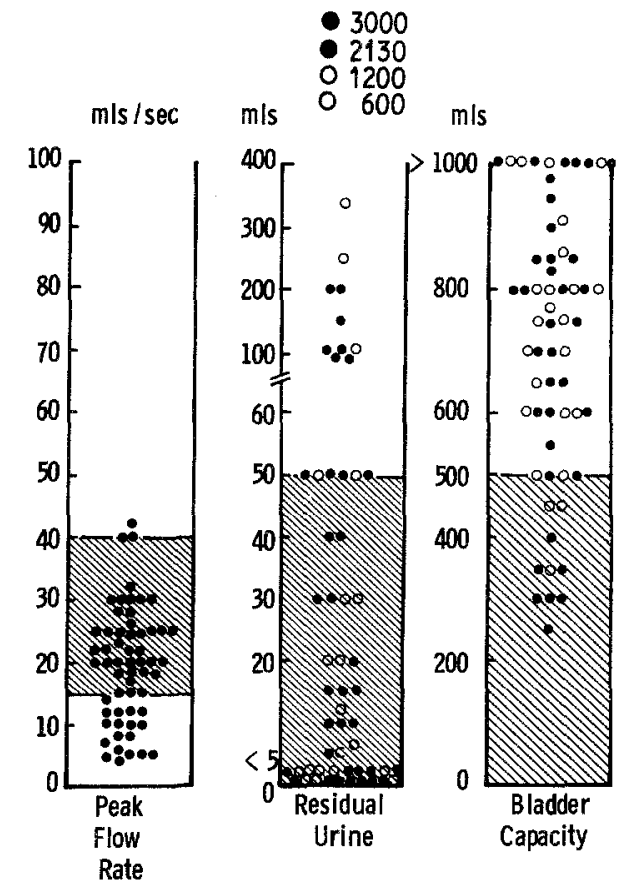

Fig. 5. The main urodynamic measurements recovered from 60 diabetic patients.

Peak urine flow rate low only in 5 with outflow tract.

Obstruction and 13 with advanced neuropathy.

Residual urine mostly normal $(<50 \mathrm{ml})$ except in 14 with impaired or paralysed detrusor function

Table 2. Gradings of uropathy due to autonomic neuropathy found and their frequency (after excluding 5 patients found to have outlet tract obstruction)

\begin{tabular}{llll}
\hline Grade & Uropathy & \multicolumn{2}{l}{ Patients } \\
\hline 0 & $\begin{array}{l}\text { Normal } \\
\text { Large capacity atonic bladder } \\
\text { with diminished sensation } \\
\text { mainly asymptomatic }\end{array}$ & 12 & $20 \%$ \\
& $\begin{array}{l}\text { (I) + increased residual } \\
\text { urine, sphincter disturbance, } \\
\text { urinary infection }\end{array}$ & 5 & $8 \%$ \\
II & $\begin{array}{l}\text { Bladder paralysis with chronic } \\
\text { III }\end{array}$ & 4 & $7 \%$ \\
\hline Totention of urine & & 55 & $92 \%$ \\
\hline
\end{tabular}

The patient was treated by permanent bladder drainage with an indwelling catheter.

It may be noted that impotence was a feature in many $(60 \%$ or $21 / 35)$ of the male patients tested. In 15 of these the typical bladder abnormality was demonstrable; in 3 others outflow tract obstruction was found, but in the remaining 3 patients, all over 65 years, no abnormality of bladder function was demonstrated. 


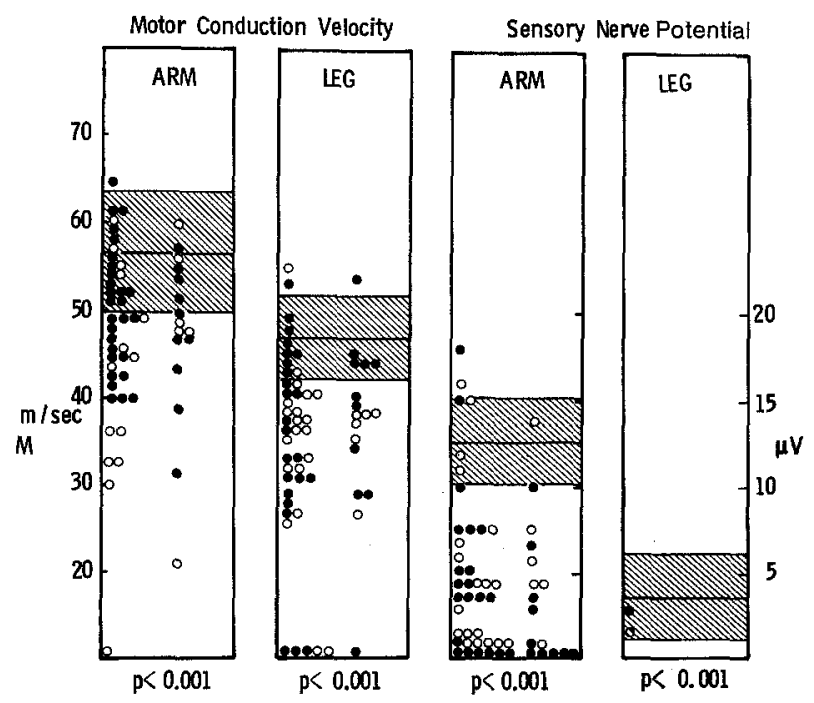

Fig. 6. The electrophysiological measurements recorded from all 60 patients. Only two had a recordable nerve action potential in the leg

\section{Electrophysiological Measurements}

Among all 60 patients $33(55 \%)$ had a reduced motor conduction velocity $(\mathrm{MCV})$ in the median nerve $(<50$ $\mathrm{m} / \mathrm{s}$ ). In these diabetic patients the mean arm MCV was $47.6 \pm 6.9 \mathrm{~m} / \mathrm{s}$ (mean $\pm \mathrm{SD}$ ), clearly lower than that in the nondiabetic controls which was $56.9 \pm 6.9$ $\mathrm{m} / \mathrm{s}$ (mean $\pm \mathrm{SD})(\mathrm{P}<0.001)$. The leg MCV in the lateral popliteal nerve showed a similar lowering among the diabetics as compared with control subjects. In the control group the mean $\mathrm{MCV}$ was $47.2 \pm 4.5 \mathrm{~m} / \mathrm{s}$, while in the diabetics it was $38.2 \pm 6.8$ $\mathrm{m} / \mathrm{s}(\mathrm{P}<0.001)$. In 25 of these patients it was less than $36 \mathrm{~m} / \mathrm{s}$. The decrease in sensory nerve action potential (arm and leg SNAP) was even more marked; the mean amplitude being $4.06 \pm 5.0 \mu \mathrm{v}$ (mean $\pm \mathrm{SD}$ ) while in the non-diabetic controls it was $12.2 \pm 2.8 \mu \mathrm{v}$ $(\mathrm{P}<0.001)$. Only 9 diabetics $(14 \%)$ had a normal arm SNAP. In the leg the SNAP was abnormal in every patient, being totally absent in 58 and reduced in the remaining 2 (Fig. 6).

The electrophysiological peripheral neuropathy may be graded by its anatomical extent as shown in Table 3. When this grading is compared with the associated symptoms and clinical signs of neuropathy, it is evident that the abnormality was often sub-clinical. Whereas all 60 diabetic subjects tested showed some electrophysiological signs of peripheral neuropathy only $30 \%$ had corresponding symptoms or clinical signs, although $80 \%$ had some symptoms of neuropathy. Impotence $(60 \%)$ or bladder symptoms $(48 \%)$ were the commonest symptoms pointing to the neuropathy, being more frequent than peripheral neuropathy symptoms $(30 \%)$ or gastrointestinal symptoms $(27 \%)$.

It is important to note the frequency of neuropathic abnormalities demonstrable among the newly diagnosed diabetics - all of the 11 tested showing peripheral neuropathy and uropathy while related symptoms were elicited only from 4 (Table 4 ).

Although there was some correlation $(\mathrm{P}<0.05)$ between the abnormalities of bladder function and the severity of diabetes judged according to whether or not the patients required insulin, this was not the case in respect of the duration of diabetes.

\section{Discussion}

Vesico-urethral dysfunction is a recognised manifestation of autonomic neuropathy in diabetes mellitus $[1,3,6]$. Histological and histochemical studies on the autonomic nerve fibres of the urinary bladder in diabetics have shown damage to nerve fibres and reduced or absent cholinesterase activity [20]. Diabetic autonomic neuropathy affecting the gastrointestinal tract and vascular reflexes has also been reported [21, $22,23,24,25]$. Earlier studies have also shown the frequency of abnormal bladder function in diabetic patients, based on clinical, radiological, endoscopic and manometric assessments $[26,3,27,5,6,8]$. In the present study measurement of urine flow rates and of urethral pressure profiles could distinguish mechanical outflow tract obstruction from a bladder neuropathy secondary to diabetes, so that any abnormalities due to the coexistence of prostatic hypertrophy in elderly male diabetics could be set aside. Our studies show that symptoms of urinary frequency, urgency and hesitancy suggestive of prostatic enlargement may be due to diabetic bladder dysfunction and correct diagnosis requires a high index of suspicion.

The most common and characteristic cystometric abnormality was a large capacity bladder with a flat tracing showing little or no pressure rise on filling. A bladder capacity of $500 \mathrm{ml}$ is regarded as the upper limit of normal $[11,28,12]$. In most patients with normal bladder sensation and normal cystometric curves the bladder capacity did not exceed $500 \mathrm{ml}$; however, there were a few patients with larger bladder capacities (up to $650 \mathrm{ml}$ ) who had a normal pressure response with intact bladder sensation and these patients were also regarded as normal. The earliest neurological deficit in diabetic patients with neurogenic bladders is said to be loss of bladder sensation due to involvement of the afferent sympathetic nerves $[3,27,29,6]$ and the increased capacity probably arises from defective perception of bladder filling. Impaired or absent bladder sensation was a common 
Table 3. The associated symptoms and clinical signs found among the electrophysiological gradings of the neuropathy

\begin{tabular}{|c|c|c|c|c|c|c|c|c|c|}
\hline \multicolumn{5}{|c|}{$\begin{array}{l}\text { Electrophysiological grading } \\
\text { of peripheral neuropathy }\end{array}$} & \multicolumn{5}{|c|}{ Associated symptoms and signs } \\
\hline \multirow[b]{2}{*}{$\begin{array}{l}\text { Grade } \\
0\end{array}$} & \multicolumn{2}{|l|}{ Leg } & \multicolumn{2}{|l|}{ Arm } & \multirow[b]{2}{*}{ Corresponding } & \multirow[b]{2}{*}{ Any } & \multicolumn{2}{|l|}{ Including } & \multirow[b]{2}{*}{$\begin{array}{l}\text { Gastrointestinal } \\
\text { and/or hypotension }\end{array}$} \\
\hline & sensory & $\begin{array}{l}\text { motor } \\
-\end{array}$ & sensory & $\begin{array}{l}\text { motor } \\
-\end{array}$ & & & Bladder & Impotence & \\
\hline $\mathrm{Ia}$ & + & - & - & - & $3 / 5$ & $4 / 5$ & $3 / 5$ & $1 / 2$ & $1 / 5$ \\
\hline Ib & + & - & + & - & $9 / 14$ & $9 / 14$ & $8 / 14$ & $7 / 11$ & $2 / 14$ \\
\hline II & + & + & - & - & $1 / 4$ & $1 / 4$ & $1 / 4$ & $0 / 1$ & $1 / 4$ \\
\hline III & + & + & + & - & $4 / 19$ & $17 / 19$ & $8 / 19$ & $6 / 10$ & $8 / 19$ \\
\hline IV & + & + & + & + & $1 / 18$ & $17 / 18$ & $9 / 18$ & $7 / 11$ & $4 / 18$ \\
\hline Total & & & & & $18 / 48(45 \%)$ & $48 / 60(80 \%)$ & $29 / 60(48 \%)$ & $21 / 35(60 \%)$ & $16 / 60(27 \%)$ \\
\hline
\end{tabular}

Table 4. Incidence of urodynamic and peripheral neuropathic abnormalities in the newly diagnosed, untreated, diabetic patients

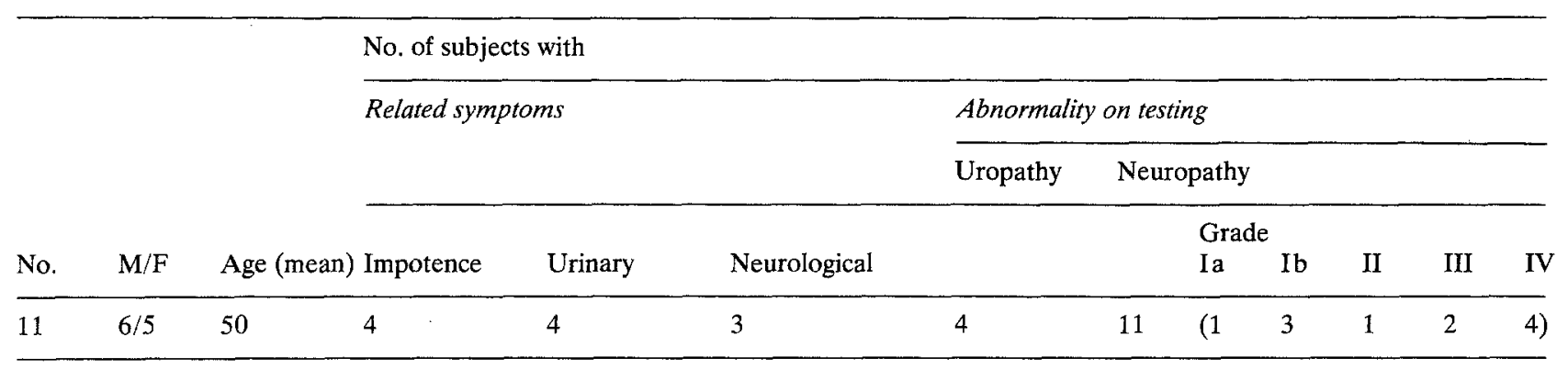

feature in our patients which could be indexed by expressing the volume at which sensation is first experienced as a percentage of the total bladder capacity; values greater than $50 \%$ indicating a sensory neurological defect [14].

This study confirmed the high incidence of bladder dysfunction in asymptomatic diabetes $[11,12,13]$; of the 34 patients $(56.7 \%)$ with a Grade I defect, 23 were asymptomatic. Progressive neuropathy with detrusor involvement together with unco-ordinated action of the detrusor and external sphincter mechanism during voiding results in poor urine flow rates, incomplete bladder emptying and infection of the residual urine (Grade II). In none of the patients with a Grade II defect did the bladder capacity exceed $800 \mathrm{ml}$; presumably chronic infection had resulted in bladder contraction with a reduced capacity. Complete bladder paralysis (Grade III defect) is rare and was seen in 4 patients only, in two of whom diabetes had been present for several years; in another patient the paralysed bladder was the initial clinical manifestation of diabetes, while the fourth patient presented with uncontrolled diabetes and painless retention of urine with overflow incontinence. In these cases other causes of a neurogenic bladder such as alcohol, syphilis, combined degeneration, tumours of and trauma to the spinal cord were excluded.

The reported incidence of impotence as a compli- cation of diabetes has varied from $27 \%$ [3] to $50 \%$ $[30,31]$. We have found that 21 of 35 male patients tested $(60 \%)$ complained of impotence and 15/21 $(71 \%)$ of these showed evidence of vesical neuropathy. When impotence is associated with other abnormalities such as bladder dysfunction [32], abnormal vascular reflexes [24], or impaired testicular sensation [33] it is most probably due to an autonomic neuropathy. Tests of androgen function including plasma testosterone, urinary 17 -Ketosteroid excretion and testicular biopsy are said to show no abnormality [32, 34].

Peripheral neuropathic changes are also often subclinical while motor as well as sensory nerves may be affected [9], but the extent to which this occurs has not been clarified. The present study has demonstrated a very high prevatence of sensory peripheral neuropathy, for it was evident on electrophysiological testing in the legs of all 60 patients studied. An associated disturbance in motor conduction was seen in 41 of these $(69 \%)$. Similar changes were found in the arms in 51 patients $(85 \%)$, in the majority of whom these were sub-clinical or associated with only mild symptoms. These findings are in accord with those of Lamontagne and Buchthal [9] who showed that even where clinical signs and symptoms of neuropathy were mild electrophysiological abnormalities were found in every patient. 
That peripheral and autonomic neuropathy coexist in diabetes is well established. It has also been suggested that a correlation is present between them [35] and that patients with abnormal vascular reflexes have a more marked disturbance of motor conduction in the legs than patients with normal vascular responses [24].

In the present study there was no correlation between patients with abnormalities of bladder function and those with nerve conduction defects in the limbs. For instance in patients with predominant autonomic bladder dysfunction there were minimal motor conduction abnormalities. Conversely some patients with severe peripheral neuropathy were seen to have normal bladder function.

Acknowledgements. We wish to thank Miss Aviva Petrie, M. Sc., for statistical analysis of the data and the Department of Medical Illustration and Photography for Figures and Tables.

\section{References}

1. Jordan, W. R., Crabtree, H. H.: Paralysis of bladder in diabetic patients. Arch. intern. Med. 55, 17-25 (1935)

2. Rudy, A., Muellner, S. R.: Neurogenic bladder in diabetes mellitus: Early recognition and treatment with report of cases. J. Urol. (Baltimore) 45, 844-857 (1941

3. Rundles, R. W.: Diabetic neuropathy; general review with report of 125 cases. Medicine (Baltimore) 24, 111-160 (1945)

4. Spring, M., Hymes, J.: Neurogenic bladder dysfunction as complication of diabetes; report of 7 cases. Diabetes 2, 199-205 (1953)

5. Larcan, A., Huriet, C., Vaillandet, M., Fauchier, J. P.: Les manifestations vésicales au cours du diabete. Presse méd. 73, 273-276 (1965)

6. Ellenberg, M.: Diabetic neurogenic vesical dysfunction. Ann. intern. Med. (Chicago) 117, 348-354 (1966)

7. Yamagata, S., Kubota, T., Yamauchi, Y., Fukuhara, N.: Early diagnosis of diabetic neuropathy and glomerulosclerosis. Proceedings of the 6th Congress of the International Diabetes Federation, p. 24. (Abstract) Stockholm: Exerpta Medica Foundation 1967

8. Fagerberg, S. E., Kock, N. G., Peteren, I., Steiner, I.: Urinary bladder disturbances in diabetics. I. A comparative study of male diabetics and controls aged between 20 and 50 years. Scand. J. Urol. Nephrol. 1, 19-27 (1967)

9. Lamontagne, A., Buchthal, F.: Electrophysiological studies in diabetic neuropathy. J. Neurol. Neurosurg. Psychiat. 33, $442-452(1970)$

10. Ward, J. D., Barnes, C. G., Fisher, D. J., Jessop, J. D., Baker, R. W. R.: Improvement in nerve conduction following treatment in newly diagnosed diabetics. Lancet $1971 \mathrm{I}, 428-430$

11. Ellenberg, M., Weber, H.: The incipient asymptomatic diabetic bladder. Diabetes 16, 331-335 (1967)

12. Faerman, I., Maler, M., Jadzinksy, M., Alvarez, E., Fox, D., Zilbervarg, J., Cibeira, J. B., Colinas, R.: Asymptomatic neurogenic bladder in juvenile diabetics. Diabetologia 7 , 168-172 (1971)

13. Buck, A. C., McRae, C. U., Reed, P. I., Chisholm, G. D.: Abnormal detrusor function in asymptomatic diabetes. Brit. J. Surg. 60, 310 (1973)
14. Buck, A. C., McRae, C. U., Reed, P. I., Chisholm, G. D.: The diabetic bladder. Proc. roy. Soc. Med. 67, 81-83 (1974)

15. Von Garrelts, B.: Analysis of micturition; a new method of recording the voiding of the bladder. Acta chir. scand. 112, 326-340 (1956)

16. Brown, M., Wickham, J. E. A.: The urethral pressure profile. Brit. J. Urol. 41, 211-217 (1969)

17. Thomas, P. K., Sears, T. A., Gilliatt, R. W.: The range of conduction velocity in normal motor nerve fibres to the small muscles of the hand and foot. J. Neurol. Neurosurg. Psychiat. 22, 175-181 (1959)

18. Gilliatt, R. W., Goodman, H. V., Willison, R. G.: The recording of lateral popliteal nerve action potentials in man. J. Neurol. Neurosurg. Psychiat. 24, 305-318 (1961)

19. Dawson, G. D.: Relative excitability and conduction velocity of sensory and motor nerve fibres in man. J. Physiol. (Lond.) 131, 436-451 (1956)

20. Faerman, I., Gocer, L., Celener, D., Jadzinsky, M., Fox, D., Maler, M., Alvarez, E.: Autonomic nervous system and diabetes. Histological and histochemical study of the autonomic nerve fibres of the urinary bladder in diabetic patients. Diabetes 22, 225-237 (1973)

21. Malins, J. M., Mayne, N.: Diabetic diarrhoea. A study of thirteen patients with jejunal biopsy. Diabetes 18, 858-866 (1969)

22. Whalen, G. E., Soergel, K. H., Geenen, J. E.: Diabetic diarrhoea. A clinical and pathophysiological study. Gastroenterology 56, 1021-1032 (1969)

23. Drewes, V. M.: The small intestine in diabetes mellitus. Copenhagen: Munksgaard 1971

24. Ewing, D. J., Campbell, I. W., Burt, A. A., Clarke, B. F.: Vascular reflexes in diabetic autonomic neuropathy. Lancet 1973 II, 1354-1356

25. Baron, J. H.: Autonomic neuropathy and autovagotomy, Brit. med. J. 3, 408-409 (1974)

26. Gill, R. D.: Diabetic (cord) bladder. J. Urol. (Baltimore) 36, $730-739$ (1936)

27. Lich, R., Jr., Grant, O.: Vesical abnormalities incident to diabetes mellitus. J. Urol. (Baltimore) 59, 863-874 (1948)

28. Bates, C. P.: Continence and incontinence. A clinical study of the dynamics of voiding and of the sphincter mechanism. Ann. roy. Coll. Surg. Engl. 49, 18-35 (1971)

29. Balfour, J., Ankenman, G. J.: Atonic neurogenic bladder as a manifestation of diabetic neuropathy. J. Urol. (Baltimore) 76, 746-752 (1956)

30. Rubin, A., Babbott, D.: Impotence and diabetes mellitus. J. Amer. med. Ass. 168, 498-500 (1958)

31. Schöffling, K., Federlin, K., Ditschuneit, H.: Disorders of sexual function in male diabetics. Diabetes 12, 519-527 (1963)

32. Ellenberg, M.: Impotence in diabetes: the neurological factor. Ann. intern. Med. 75, 213-219 (1971)

33. Campbell, I. W., Ewing, D. J., Clarke, B. F., Duncun, L. J. P.: Testicular pain sensation in diabetic autonomic neuropathy. Brit. med. J. 2, 638-639 (1974)

34. Faerman, I., Vilar, O., Rivarola, M. A., Rosner, J., Jadzinsky, M., Fox, D., Perez-Lloret, A., Bernstein-Hahn, L., Saracent, D.: Impotence and diabetes. Studies of androgenic function in diabetic impotent males. Diabetes 21, 23-30 (1972)

35. Bishnu, S. K., Berenyi, M. R.: Circulatory reflex response in diabetic patients with or without peripheral neuropathy. $J$. Amer. Geriat. Soc. 19, 159-196 (1971)

Received: November 27, 1975, and in revised form: March 30, 1976

Dr. P. I. Reed

Dept. of Medicine

Royal Postgraduate Medical School

Hammersmith Hospital

London W12 OHS

England 